\title{
Ribonucleic Acid (RNA)
}

National Human Genome Research Institute (NHGRI)

\section{Source}

National Human Genome Research Institute (NHGRI). Ribonucleic Acid (RNA).
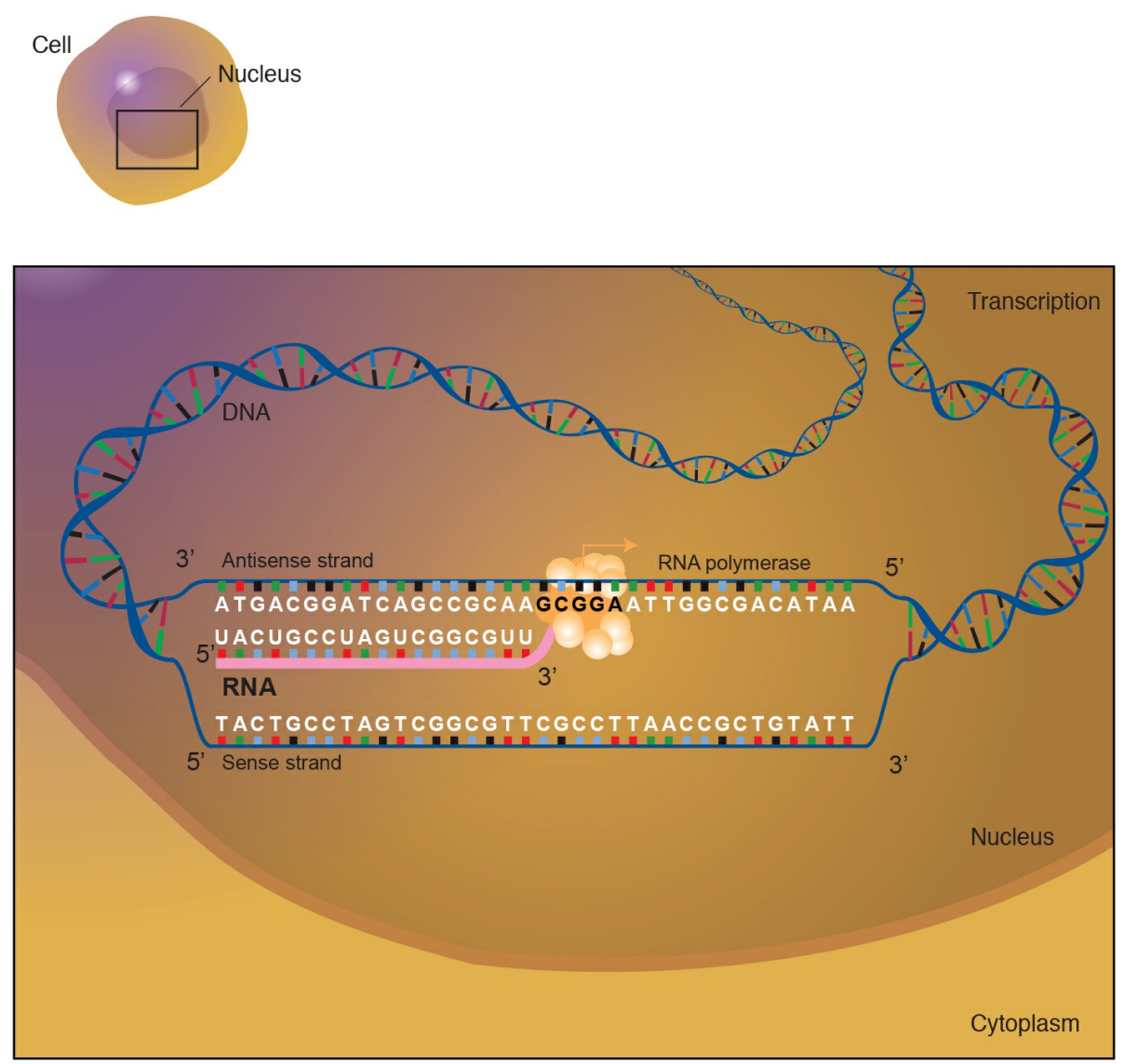

Ribonucleic acid (RNA) is a molecule similar to DNA. Unlike DNA, RNA is single-stranded. An RNA strand has a backbone made of alternating sugar (ribose) and phosphate groups. Attached to each sugar is one of four bases--adenine (A), uracil (U), cytosine (C), or guanine (G). Different types of RNA exist in the cell: messenger RNA (mRNA), ribosomal RNA (rRNA), and transfer RNA (tRNA). More recently, some small RNAs have been found to be involved in regulating gene expression. 